spearhead the pursuit to optimize management in this heterogeneous disease.

\section{References}

1. Cui H, Schaff HV, Geske JB, Lahr BD, Dearani JA, Nishimura RA, et al. Early septal reduction therapy for patients with obstructive hypertrophic cardiomyopathy. J Thorac Cardiovasc Surg. 2022;164:1502-9.e5.

2. American College of Cardiology Foundation/American Heart Association Task Force on Practice, American Association for Thoracic Surgery, American Society of Echocardiography, American Society of Nuclear Cardiology, Heart Failure Society of America, Heart Rhythm Society, et al. 2011 ACCF/AHA guideline for the diagnosis and treatment of hypertrophic cardiomyopathy: a report of the American College of Cardiology Foundation/American Heart Association task force on practice guidelines. J Thorac Cardiovasc Surg. 2011;142:e153-203.

3. Authors/Task Force Members, Elliott PM, Anastasakis A, Borger MA, Borggrefe M, Cecchi F, et al. 2014 ESC guidelines on diagnosis and management of hypertrophic cardiomyopathy: the task force for the diagnosis and management of hypertrophic cardiomyopathy of the European Society of Cardiology (ESC) Eur Heart J. 2014;35:2733-79.

4. Cavigli L, Fumagalli C, Maurizi N, Rossi A, Arretini A, Targetti M, et al. Timing of invasive septal reduction therapies and outcome of patients with obstructive hypertrophic cardiomyopathy. Int J Cardiol. 2018;273:155-61.

5. Huurman R, Schinkel AFL, de Jong PL, van Slegtenhorst MA, Hirsch A, Michels M, et al. Impact of sex on timing and clinical outcome of septal myectomy for obstructive hypertrophic cardiomyopathy. Int J Cardiol. August 22, 2020 [Epub ahead of print].

6. Maron BJ, Dearani JA, Ommen SR, Maron MS, Schaff HV, Nishimura RA, et al Low operative mortality achieved with surgical septal myectomy: role of dedicated hypertrophic cardiomyopathy centers in the management of dynamic subaortic obstruction. J Am Coll Cardiol. 2015;66:1307-8.

7. Sorajja P, Nishimura RA, Gersh BJ, Dearani JA, Hodge DO, Wiste HJ, et al. Outcome of mildly symptomatic or asymptomatic obstructive hypertrophic cardiomyopathy: a long-term follow-up study. J Am Coll Cardiol. 2009;54:234-41.

8. Meng X, Liang M, Shi Y, Zhou S, Zhang W, Gao C. Effects of surgical septa myectomy on survival in patients with hypertrophic obstructive cardiomyopathy. Anatol J Cardiol. 2020;23:342-8.

\title{
Commentary: Invasive therapy for hypertrophic obstructive cardiomyopathy: Is it time to reexamine the guidelines?
}

\author{
Amine Mazine, MD, MSc, Derrick Y. Tam, MD, PhD, \\ and Stephen E. Fremes, MD, MSc
}

Hypertrophic obstructive cardiomyopathy (HOCM) is associated with reduced life expectancy and quality of life, ${ }^{1,2}$ even in asymptomatic or mildly symptomatic patients. ${ }^{3}$ Previous observational studies have shown that septal reduction therapy (SRT) in the form of surgical septal myectomy restores long-term survival in HOCM patients to that of the age- and sex-matched general population. ${ }^{4}$ Nonetheless, both European and American practice

\footnotetext{
From the Division of Cardiac Surgery, Schulich Heart Centre, Department of Surgery, Sunnybrook Health Sciences Centre, University of Toronto, Toronto, Ontario, Canada. Disclosures: The authors reported no conflicts of interest.

The Journal policy requires editors and reviewers to disclose conflicts of interest and to decline handling or reviewing manuscripts for which they may have a conflict of interest. The editors and reviewers of this article have no conflicts of interest.

Received for publication Nov 2, 2020; revisions received Nov 2, 2020; accepted for publication Nov 3, 2020; available ahead of print Nov 7, 2020.

Address for reprints: Stephen E. Fremes, MD, MSc, Dr Bernard S. Goldman Chair in Cardiovascular Surgery, Schulich Heart Centre, Sunnybrook Health Sciences Centre, 2075 Bayview Ave, Room H4 05, Toronto, ON, Canada M4N 3M5 (E-mail: Stephen.fremes@sunnybrook.ca).

J Thorac Cardiovasc Surg 2022;164:1511-3 0022-5223/ $\$ 36.00$

Copyright (c) 2020 Published by Elsevier Inc. on behalf of The American Association for Thoracic Surgery

https://doi.org/10.1016/j.jtcvs.2020.11.008
}

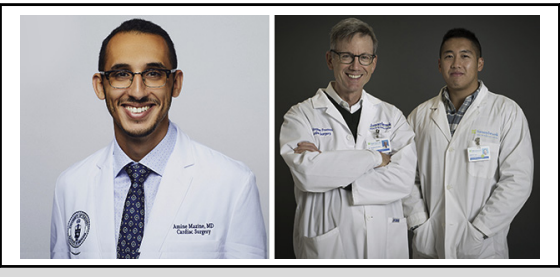

Amine Mazine, MD, MSc, Stephen E. Fremes, MD, MSc, and Derrick Y. Tam, MD, PhD

CENTRAL MESSAGE
In experienced centers, early
septal reduction therapy is
associated with improved
long-term survival in women and
symptomatic patients with
hypertrophic obstructive
cardiomyopathy.

guidelines recommend that SRT be reserved for patients whose symptoms are refractory to medical treatment (class $\mathrm{I}$; level of evidence, $\mathrm{B}$ in European guidelines and $\mathrm{C}$ in American guidelines). ${ }^{5,6}$ Furthermore, there remains a paucity of data to guide the optimal timing of invasive treatment of patients with HOCM.

In this issue of the Journal, Cui and colleagues ${ }^{7}$ attempt to address this gap in knowledge and challenge the existing paradigm of treating only those with refractory symptoms. This article represents another important contribution from the Mayo Clinic on the treatment of HOCM. In this 
single-center study of 1351 patients with HOCM who met objective criteria for surgery-defined as a minimal left ventricular outflow tract pressure gradient of $30 \mathrm{~mm} \mathrm{Hg}$ (at rest) or $50 \mathrm{~mm} \mathrm{Hg}$ (provoked) - the authors compare long-term survival of HOCM patients referred to their center according to initial management strategy. Patients who underwent septal myectomy or alcohol septal ablation during the first 6 months after index evaluation were assigned to the "early SRT" group $(\mathrm{n}=884 ; 65 \%)$, and the remaining 467 patients $(35 \%)$ were assigned to the "medical treatment" group (regardless of whether they underwent SRT after the initial 6-month period).

In a landmark analysis at 6 months, early mortality was $0.8 \%$ (7 of 891 ) in the early SRT group versus $0.6 \%$ (3 of 470) in the medical treatment group. After the 6-month landmark period, patients who underwent early SRT had similar long-term survival as those treated medically, despite being sicker (early SRT vs medical treatment: hazard ratio [HR], 0.85; 95\% confidence interval [CI], 0.66$1.10 ; P=.207)$. After adjustment for differences in baseline characteristics using a multivariable Cox model, long-term survival was improved in the early SRT group (HR, 0.66; $95 \% \mathrm{CI}, 0.48-0.90 ; P=.010)$. In addition, subgroup analyses revealed significant treatment heterogeneity, with a survival benefit observed in females and symptomatic (ie, NYHA class III or IV) patients undergoing early SRT. Finally, of the 467 patients who did not undergo early SRT, 119 underwent late SRT after the 6-month landmark period. No survival difference was observed between early and late SRT, and patients who underwent late SRT also had a survival benefit compared with those who continued medical treatment.

This study must be interpreted in the context of some significant limitations. There are the usual limitations associated with observational studies given the baseline differences between the 2 groups. Those patients who underwent early SRT were much more symptomatic and had a higher resting gradient. Importantly, we must acknowledge that the Mayo Clinic is an established tertiary referral center for HOCM, which raises questions about the generalizability of these findings. It also introduces the potential for selection bias, as a majority of patients included in this study were already under the care of a cardiologist before being evaluated at the Mayo Clinic, and those with milder symptoms that responded to medical therapy might have not been referred. Thus, results from this study should be interpreted in conjunction with findings of previous reports that have demonstrated an advantage of early versus delayed referral to SRT from diagnosis in HOCM patients. ${ }^{8}$ Furthermore, the authors report no data beyond mortality. Given the reduced quality of life associated with HOCM, examining the impact of early SRT versus medical treatment on quality of life would have strengthened the conclusions of this study. In addition, the early SRT group was heterogeneous and included patients who underwent septal myectomy $(\mathrm{n}=776)$ and those who underwent alcohol septal ablation $(\mathrm{n}=108)$. The authors did not compare outcomes between these 2 subgroups, and it is unclear whether the observed treatment effect was consistent between the 2 forms of SRT. In addition, those in the early SRT group underwent associated surgical procedures, which may have contributed to the benefit seen with intervention. The use of a 6-month landmark analysis introduces an immortal time bias for those in the early SRT group, whereas those who were initially medically managed were at risk for procedural mortality when they eventually underwent late SRT. Finally, despite extensive risk adjustment, there is the potential for unknown or unmeasured confounders to influence both treatment allocation and outcomes.

These limitations notwithstanding, the results from this large study provide an important addition to the current body of literature on the treatment of HOCM. The findings reported by Cui and colleagues suggest that there was no harm associated with early SRT at their institution, and that particular subgroups may benefit substantially from early SRT. Overall, these findings warrant careful reexamination of current practice guidelines, which emphasize medical treatment of symptomatic patients with obstructive HOCM. ${ }^{5,6}$ These recommendations are based on studies from an earlier era when surgical mortality for septal myectomy was much higher. In the current era, mortality for surgical myectomy is $<1 \%$ in experienced centers. ${ }^{9,10}$ As such, expertise-based recommendations, similar to those in place for the treatment of severe asymptomatic mitral regurgitation, should be considered in future iterations of guidelines for the treatment of HOCM.

\section{References}

1. Maron MS, Olivotto I, Betocchi S, Casey SA, Lesser JR, Losi MA, et al. Effect of left ventricular outflow tract obstruction on clinical outcome in hypertrophic cardiomyopathy. N Engl J Med. 2003;348:295-303.

2. Elliott PM, Gimeno JR, Tomé MT, Shah J, Ward D, Thaman R, et al. Left ventricular outflow tract obstruction and sudden death risk in patients with hypertrophic cardiomyopathy. Eur Heart J. 2006;27:1933-41.

3. Sorajja P, Nishimura RA, Gersh BJ, Dearani JA, Hodge DO, Wiste HJ, et al. Outcome of mildly symptomatic or asymptomatic obstructive hypertrophic cardiomyopathy: a long-term follow-up study. J Am Coll Cardiol. 2009;54:234-41.

4. Ommen SR, Maron BJ, Olivotto I, Maron MS, Cecchi F, Betocchi S, et al. Longterm effects of surgical septal myectomy on survival in patients with obstructive hypertrophic cardiomyopathy. J Am Coll Cardiol. 2005;46:470-6.

5. Elliott PM, Anastasakis A, Borger MA, Borggrefe M, Cecchi F, Charron P, et al. 2014 ESC guidelines on diagnosis and management of hypertrophic cardiomyopathy: the task force for the diagnosis and management of hypertrophic cardiomyopathy of the European Society of Cardiology (ESC). Eur Heart J. 2014;35: 2733-79.

6. Gersh BJ, Maron BJ, Bonow RO, Dearani JA, Fifer MA, Link MS, et al. 2011 ACCF/AHA guideline for the diagnosis and treatment of hypertrophic cardiomyopathy: a report of the American College of Cardiology Foundation/American Heart Association task force on practice guidelines. Developed in collaboration with the American Association for Thoracic Surgery, American Society of Echocardiography, American Society of Nuclear Cardiology, Heart Failure Society of America, Heart Rhythm Society, Society for Cardiovascular Angiography and Interventions, and Society of Thoracic Surgeons. J Am Coll Cardiol. 2011;58: e212-60. 
7. Cui H, Schaff HV, Geske JB, Lahr BD, Dearani JA, Nishimura RA, et al. Early septal reduction therapy for patients with obstructive hypertrophic cardiomyopathy. J Thorac Cardiovasc Surg. 2022;164:1502-9.e5.

8. Cavigli L, Fumagalli C, Maurizi N, Rossi A, Arretini A, Targetti M, et al. Timing of invasive septal reduction therapies and outcome of patients with obstructive hypertrophic cardiomyopathy. Int J Cardiol. 2018; 273:155-61.
9. Maron BJ, Dearani JA, Ommen SR, Maron MS, Schaff HV, Nishimura RA, et al. Low operative mortality achieved with surgical septal myectomy: role of dedicated hypertrophic cardiomyopathy centers in the management of dynamic subaortic obstruction. J Am Coll Cardiol. 2015;66:1307-8.

10. Mazine A, Ghoneim A, Bouhout I, Fortin W, Berania I, L'Allier PL, et al. A novel minimally invasive approach for surgical septal myectomy. Can J Cardiol. 2016; $32: 1340-7$.
See Article page 1502.

\section{Commentary: Septal reduction therapy: The sooner, the better?}

\author{
Lawrence M. Wei, MD
}

What is the impact of early septal reduction therapy (SRT) on patients with obstructive hypertrophic cardiomyopathy (HCM)? In this issue of the Journal, Cui and colleagues ${ }^{1}$ present a study of 1351 patients with obstructive HCM evaluated at the Mayo Clinic from 2000 to 2012. Early SRT, defined as septal myectomy (SM) or alcohol septal ablation (ASA) within 6 months of index evaluation, was performed in 884 patients $(65.4 \%)$, whereas 467 patients $(34.6 \%)$ were initially treated medically. Follow-up starting at the 6-month landmark point as "time zero" continued for 15 years (median, 10 years), with mortality the primary endpoint.

The most striking finding, clearly illustrated in the article's central picture, is that early SRT provides a survival benefit compared with medical treatment. This difference was even more pronounced after the patients were riskadjusted for age and comorbidities. There was heterogeneity of treatment effect, with increased benefit of early SRT in women, patients in New York Heart Association class IIIIV, and nondiabetics.

\footnotetext{
From the Department of Cardiovascular and Thoracic Surgery, West Virginia University, Morgantown, WVa.

Disclosures: The author reported no conflicts of interest.

The Journal policy requires editors and reviewers to disclose conflicts of interest and to decline handling or reviewing manuscripts for which they may have a conflict of interest. The editors and reviewers of this article have no conflicts of interest.

Received for publication Nov 8, 2020; revisions received Nov 8, 2020; accepted for publication Nov 11, 2020; available ahead of print Nov 20, 2020.

Address for reprints: Lawrence M. Wei, MD, Department of Cardiovascular and Thoracic Surgery, West Virginia University Heart and Vascular Institute, PO Box 8003, One Medical Center Drive, Morgantown, WV 26506 (E-mail: lawrence. wei@wvumedicine.org).

J Thorac Cardiovasc Surg 2022;164:1513-4

$0022-5223 / \$ 36.00$

Copyright (C) 2020 by The American Association for Thoracic Surgery

https://doi.org/10.1016/j.jtcvs.2020.11.035
}

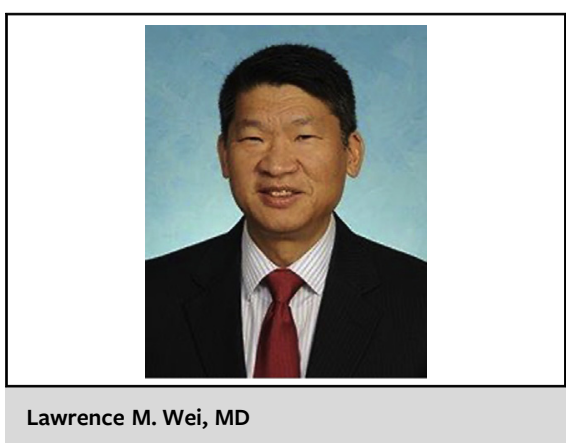

CENTRAL MESSAGE

Early septal reduction therapy

(SRT) may provide a survival

benefit over medical

management.

There are some limitations to the study, in that it is a retrospective, nonrandomized study at a tertiary referral center that performs SRT with excellent outcomes and thus might not be applicable to all institutions. It is important to note that "early" refers to the course of management and not to the disease stage. Patients with HCM may be diagnosed at various points in the disease process, some by screening and others by clinical presentation. They may be referred at varied points after diagnosis, making time from referral rather than time from diagnosis an appropriate basis for the study's design. The patients in this study are highly selected, having been referred to a tertiary care center for treatment, and the results of this study cannot be generalized to all patients diagnosed with obstructive HCM.

Septal myectomy is safe and effectively eliminates outflow tract obstruction in HCM, providing excellent relief of heart failure symptoms. ${ }^{2}$ Alcohol septal ablation is a viable alternative to SM for many patients, especially those at high surgical risk. ${ }^{3}$ However, current guidelines, based on 